\title{
Non-opposable triphalangeal thumb in an Italian family
}

\author{
A WARM, C DI PIETRO, F D'AGROSA, M CAMBIE, AND F GABOARDI \\ From the Department of Pediatrics, Ospedale A Uboldo, Cernusco S/N (Milano), Italy.
}

SUMmaRY This report describes a family with bilateral non-opposable triphalangeal thumb, bringing to two the number of families with this autosomal dominant disorder.

Triphalangeal thumb is a very rare congenital deformity. ${ }^{1}$ It has been described both as an isolated defect and in association with other limb or internal abnormalities. In 1962 Swanson and Brown ${ }^{2}$ observed a family in which 30 members in five generations manifested non-opposable triphalangeal thumbs bilaterally. We report a second family in which the affected persons had a similar malformation.

\section{Case report}

CASE 1

A male infant (V.2, fig 1) was born by spontaneous vaginal delivery at 40 weeks' gestation following an uneventful pregnancy, birth weight $3.4 \mathrm{~kg}$. He had a 'finger-like thumb' (fig 2) on both hands and a supernumerary digit originating from the radial surface of the left hand. No other limb anomalies were noted. Radiographs of the hands showed a third extra phalanx in both 'thumbs' and a rudimentary extra digit which seemed to originate from the first left metacarpal bone. There were no cardiac, haematological, visceral, ear, chromosomal, or dermatoglyphic abnormalities.

CASE 2

The older sister (V.1), aged five years, had a similar bilateral 'thumb' anomaly (fig 2 ). No polydactyly or other limb malformations were found. The 'thumbs' could not be opposed. Radiographs showed five triphalangeal digits on each hand and a distal epiphysis in the first metacarpal (fig 3). Physical examination and laboratory investigations showed no further abnormalities. The growth and development of both children is, so far, completely normal.

CASE 3

The father (IV.3) of these children, aged 32, had a 'digit-like thumb' only on the left hand (fig 2). On the right hand he had a rudimentary hypoplastic 'thumb' without a nail and scar tissue between the 'thumb' and the forefinger. Radiological studies of the hands confirmed the presence of a triphalangeal 'thumb' on the left, a hypoplastic biphalangeal 'thumb' on the right, and an osseous notch on the first right metacarpal resulting from a supernumerary digit removed surgically immediately after birth.

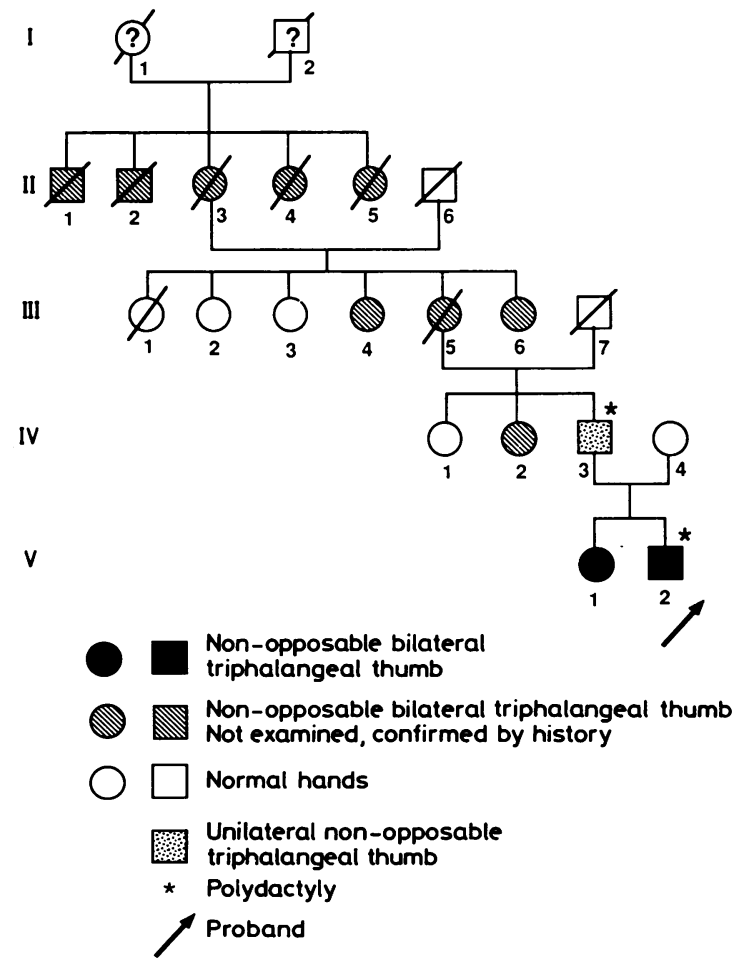

FIG 1 Family pedigree. 


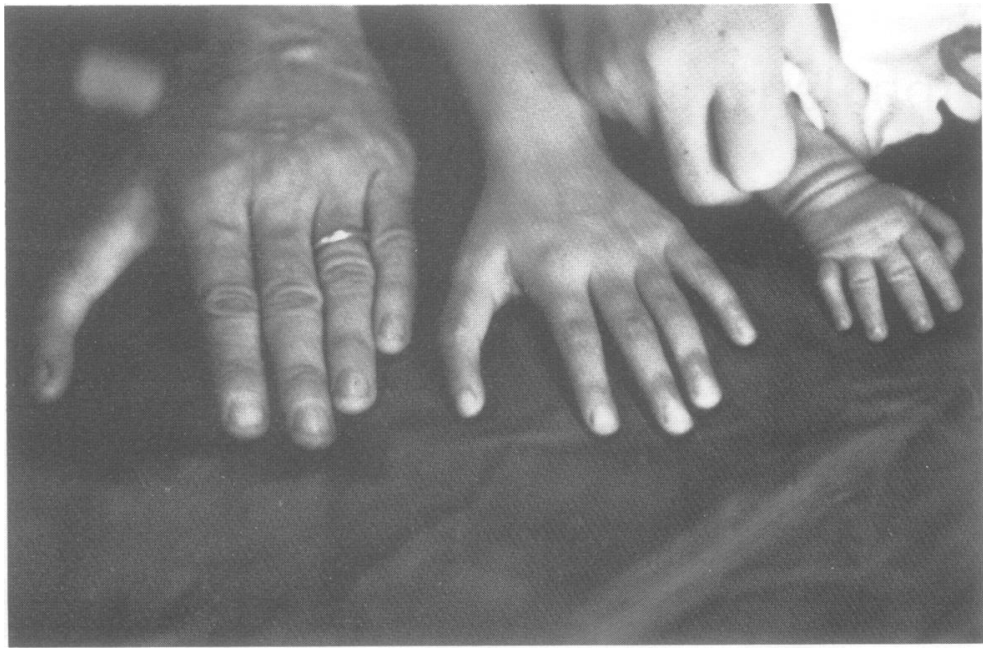

FIG 2 Cases 1 to 3 from right to left. Note 'digit-like thumb'.

Further data regarding this minor surgery were not available.

As is shown in the four generation pedigree (fig 1), nine other members had a bilateral 'digit-like thumb' not associated with other

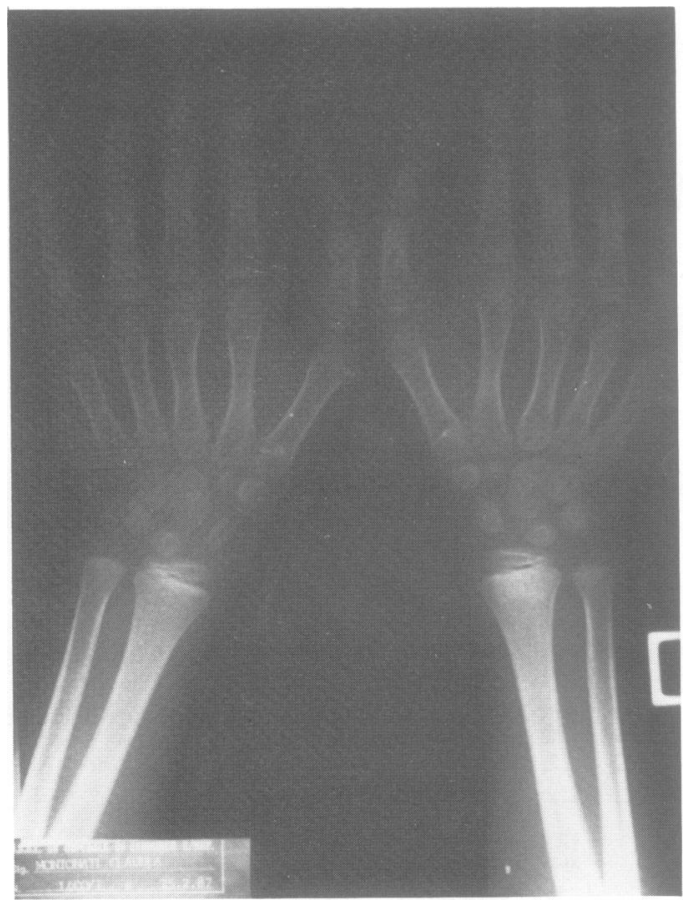

FIG $3 X$ rays of hands of case 2. Note bilateral triphalangeal 'thumb' and the distal epiphysis in the first metacarpal. deformities. We were informed that none of them could oppose their 'thumbs'.

\section{Discussion}

Within the reported family, 11 members in four generations had bilateral non-opposable triphalangeal 'thumb'. One subject manifested this defect only unilaterally, while the contralateral biphalangeal nail-less 'thumb' was hypoplastic. Polydactyly was noted in two members but the type could not be determined. In the first family described with this disorder, ${ }^{2}$ three persons had polydactyly as well. Thus, it seems that both non-opposable triphalangeal thumb and polydactyly are manifestations of the same mutant gene but with variable clinical expression. Inheritance appears to be autosomal dominant.

The clinical and radiological findings encountered in this family were different from those found in other autosomal dominant types of triphalangeal thumb, that is, triphalangeal thumb with double phalanges, ${ }^{3}$ triphalangeal thumb and dislocation of the patella, ${ }^{4}$ and triphalangeal thumb with brachyectrodactyly. ${ }^{5}$ We have also excluded a number of syndromes in which triphalangeal thumb is associated either with hypoplasia of the bone marrow (Fanconi pancytopenia, TAR, and Aase syndrome) or with other conditions (Holt-Oram syndrome, trisomy 13, and fetal hydantoin syndrome).

In view of both the radiological findings noted, that is, the presence of a distal epiphysis in the first metacarpal, which is normal for the other metacarpals, and the 'finger-like' appearance of the first non-opposable digit, we propose that this entity should not be defined as non-opposable triphalangeal thumb but as a duplication of the second 
metacarpal and digit with aplasia (or hypoplasia) of the first metacarpal and thumb.

\section{References}

1 Temtamy SA, McKusick VA. The genetics of hand malformations. Birth Defects: Original Article Series. New York: Alan R Liss, 1978;XIV,No 3.

2 Swanson AB, Brown KS. Hereditary triphalangeal thumb. $J$ Hered 1962;53:259-65.

3 Ecke H. Beitrag zu den Doppelmissbildungen in Bereich der Finger. Beitr Klin Chir 1962;205:463-8.
+ Say B. Field E. Coldwell JG. Warnberg L. Atasu M. Polydactyly with triphalangeal thumbs, brachydactyly, camptodactyly. congenital dislocation of the patellas. short stature and borderline intelligence. Birth Defects 1976:XII(5):279-86.

5 Carnevale A. Hernandez M. Del Castillo V. Torres P. A new syndrome of triphalangeal thumbs and brachy-ectrodactyly. Clin Genet 1980:18:244-52.

Correspondence and requests for reprints to $\operatorname{Dr} \mathrm{A}$ Warm, Divisione di Pediatria, Ospedale A Uboldo, Via Uboldo 2, 20063 Cernusco S/N (Milano), Italy. 